\title{
Dynamics of dry matter and selenium accumulation in oilseed rape (Brassica napus L.) in response to organic and inorganic selenium treatments
}

\author{
Nashmin Ebrahimia,c, , Helinä Hartikainen ${ }^{b}$, Asko Simojoki ${ }^{b}$, Roghieh Hajiboland ${ }^{c}$, Mervi Seppänena \\ a Department of Agricultural Sciences, University of Helsinki, Finland 'bepartment of Food and Environmental Sciences, \\ University of Helsinki, Finland \\ 'Department of Plant Biology, University of Tabriz, Iran \\ e-mail: nashmin.ebrahimi@helsinki.fi
}

\begin{abstract}
The uptake by and subsequent translocation of selenium (Se) within the plant is dependent on its chemical form and soil properties that dictate this trace element's bioavailability. Plant species differ in their tendency to accumulate Se. Se taken-up by plants is returned to soil in plant residues, but the bioavailability of organic Se in those residues is poorly known. We investigated the impact of inorganic $\left(\mathrm{Na}_{2} \mathrm{SeO}_{4}\right)$, organic (Se-enriched stem and leaf residues) Se applications and also soil microbial respiration on the growth and Se concentrations of various plant organs of oilseed rape (Brassica napus L.) during its development from the rosette to the seed filling stage. Both inorganic and organic Se slightly improved plant growth and enhanced plant development. Inorganic Se was more bioavailable than the organic forms and resulted in 3-fold to 6-fold higher Se concentrations in the siliques. Inorganic Se in autoclaved soil tended to elevate the Se concentration in all plant parts and at all growth stages. The organic Se raised Se concentrations in plants much less effectively than the inorganic selenate. Therefore, the use of inorganic Se is still recommended for biofortification.
\end{abstract}

Key words: biofortification, selenium concentration, sodium selenate, Se-enriched plant residue, soil respiration

\section{Introduction}

Selenium (Se) is a key element in the functioning of glutathione peroxidase (GPx), an important antioxidant enzyme, and therefore an essential nutrient for humans, animals and microorganisms (Terry et al. 2000, Rayman 2002). Many studies have shown its crucial effect on the health of humans and livestock. Severe Se deficiency can result in white muscle disease (also known as muscular dystrophy), which is a condition that inter alia affects the heart and skeletal-muscle in livestock (Combs 2001). A deficiency in Se can also result in hypothyroidism, asthma and weakened immune systems in humans (Combs 2001 and 2004, Whanger 2004). A large proportion of the world's human population has inadequate Se intake in the diet. Thus, it is important to design methods and agronomy practices to increase the concentration of Se in foodstuffs (Combs 2001).

Biofortification of plants by Se-supplemented fertilizers has been a successful nationwide project in Finland (Alfthan et al. 2014). Although the roles of Se in plant physiology are still emerging, Se is known to be transferred into the food chain by plants. Several studies indicate that Se can exert beneficial effects on different plant physiological processes, including growth and development of the plant (Singh et al. 1980, Hartikainen and Xue 1999), photosynthesis (Germ et al. 2005), senescence (Xue et al. 2001, Djanaguiraman et al. 2005) and increased stress tolerance (Pilon-Smits et al. 2009).

A low dosage of Se can enhance the resistance of plants to different stresses, which can probably be attributed to its antioxidative properties as a constituent of GPx (Kong et al. 2005, Hawrylak-Novak 2009). Such stresses include heavy metals ingestion (Filek et al. 2008), oxidative stress (Seppänen et al. 2003) and UV irradiation (Xue and Hartikainen 2000). Selenium was reported to increase the growth and yield of Indian mustard (Brassica juncea L.) (Singh et al. 1980), Brassica rapa (Lyons et al. 2009), lettuce (Lactuca sativa L.) and Italian ryegrass (Lolium perenne L.) (Hartikainen et al. 1997, Hartikainen and Xue 1999), soybean (Glycine max (L.) Merr.) (Djanaguiraman et al. 2005) and pumpkin (Cucurbita pepo L.) (Germ et al. 2005). Selenium was also reported to delay senescence in lettuce (Hartikainen and Xue 1999), increase starch content in potato (Solanum tuberosum L.) tubers and alfalfa (Medicago sativa L.) leaves (Turakainen et al. 2004, Owusu-Sekyere et al. 2013) and to induce defence mechanisms in plants against herbivores and fungi (Hanson et al. 2004, Freeman et al. 2009). 
In addition, the net assimilation rate of carbon in alfalfa (Medicago sativa L.) plants can be positively affected by Se application (Owusu-Sekyere et al. 2013), which was probably caused by elevating the activity of fructose 1,6 -bisphosphatase enzyme, a key enzyme of carbon assimilation.

In terms of Se accumulation, plants can be classified into three modes: non-accumulators $\left(<25 \mu \mathrm{g} \mathrm{g}^{-1} \mathrm{DM}\right)$, indi-

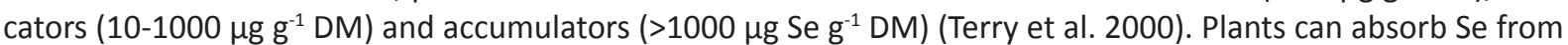
the soil in inorganic forms such as selenate $\left(\mathrm{SeO}_{4}^{-2}\right)$ and selenite $\left(\mathrm{SeO}_{3}{ }^{-2}\right)$ or in organic form such as selenomethionine (SeMet). The most available form, selenate, (Bañuelos and Schrale 1989, Zayed et al. 1998) is absorbed by sulfate transporters in the roots (Terry et al. 2000). When translocated within the shoot Se is incorporated into organic compounds by sulfate assimilation enzymes (Terry et al. 2000). Selenite, by comparison, is less bioavailable to plants because of its higher sorption onto soil particles. It is however taken up by phosphate transporters (Terry et al. 2000). A significant proportion of Se can also be found in soil organic matter (Keskinen et al. 2009). Plant species, Se speciation, microbial activity and chemical properties of soil such as the surface area of available sorption components and $\mathrm{pH}$ influence can all influence Se uptake and its subsequent translocation inside plants (Terry et al. 2000, White et al. 2004).

The impact of added Se on the activity and species distribution of soil microorganisms, plant growth and the capability of Se to volatilize has been widely studied (Hassoun et al. 1995, Chasteen and Bentley 2003, Vallini et al. 2005, Stolz et al. 2006, Lechenne et al. 2007). Knowledge about the microbial contribution to the uptake and accumulation of Se in plants is, however, rather limited. De Souza et al. (1999) proposed that the rhizosphere bacteria of Indian mustard can enhance Se accumulation and volatilization. Lindblom et al. (2012) showed that microbial activity in the rhizosphere affects the speciation and localization of Se in accumulator plants.

The bioavailability of different inorganic forms of Se for plants has been widely investigated, but few published studies on the bioavailability of organic Se as a constituent of plant residues exist (Stavridou et al. 2012). Seppänen et al. (2010) reported that a large proportion of Se applied as fertilizer is returned to the soil as plant residues. Therefore, Se-enriched plant residues can be a potential source of Se. Soils in Finland are low in bioavailable Se, therefore multi-nutrient fertilizers have been enriched with sodium selenate $\left(\mathrm{Na}_{2} \mathrm{SeO}_{4}\right)$ since 1984 (Eurola et al. 2004). Nevertheless, there is little information on the recycling of fertilizer Se, i.e. Se in the soil being taken up and metabolized by plants and then returned back to soil as a constituent of plant residues. Oilseed rape Brassica napus L. (Canola in the U.S.) is one of the most important oilseed crops for food and feed in northern Europe. $B$. napus $L$. is known to tolerate Se and thus, it can be expected to be an efficient Se accumulator. The aim of the present study was to compare the dynamics of dry matter and Se accumulation in B. napus L. that had been treated with inorganic or organic forms of Se. We also monitored the effects of Se additions on soil properties and photosynthetic activity of plants to gain further knowledge of the factors involved.

\section{Materials and methods}

\section{Cultivation of plants}

We carried out a greenhouse based experiment whereby the seeds of oilseed rape (Brassica napus L. cv. 'Westar') were sown into the pots filled with $1.5 \mathrm{~kg}$ of fine sandy soil that was high in organic matter (collected from the Viikki Research Farm, Helsinki, Finland, $60.224^{\circ} \mathrm{N}, 25.021^{\circ} \mathrm{E}$; soil pH 6.5). The contents of nutrients extracted $\left(\mathrm{mg} \mathrm{kg}^{-1}\right)$ from soil by $0.5 \mathrm{M} \mathrm{NH}_{4} \mathrm{OAc}(\mathrm{pH} 4.65$ soil to solution ratio 1:50) were as follows: Ca 2100, P 22, K 250, Mg 200, Cu 14, $\mathrm{Mn}$ 9.6, Zn 6.77 and S 13. Two $\mathrm{Na}_{2} \mathrm{SeO}_{4}$ solutions ( 25 and $504 \mu \mathrm{M}$ ) were prepared and added to the soil in quantities to obtain the Se dosages of $7 \mu \mathrm{g} \mathrm{kg}^{-1}$ (low) and $140 \mu \mathrm{g} \mathrm{kg}^{-1}$ (high) Se in the study soil treatments. The inorganic control pots were cultivated without added Se. The ground-up Se-enriched stem ( $21 \mathrm{~g})$ or leaf $(17 \mathrm{~g})$ residues of B. napus L. were used as the two types of organic Se additions corresponding to the low Se level ( $\left.7 \mu \mathrm{g} \mathrm{kg}{ }^{-1} \mathrm{soil}\right)$. Organic materials that were non-enriched with Se were used as organic controls. The Se-enriched stem and leaf materials of $B$. napus L. plants were obtained from a field experiment where $20 \mathrm{~g}$ of $\mathrm{Se} \mathrm{ha}^{-1} \mathrm{as} \mathrm{Na}_{2} \mathrm{SeO}_{4}$ had been applied B. napus L. plants (Seppänen et al. 2010).

In order to study the role of soil microorganisms on the Se uptake by plants, two further treatments with autoclaved soil (2-2.5 bar, $105-108^{\circ} \mathrm{C}, 40$ min duration) were included in the experiment. Half of the pots with autoclaved soil were amended with inorganic $\mathrm{Se}\left(\mathrm{Na}_{2} \mathrm{SeO}_{4}\right)$ dosage of $7 \mu \mathrm{g} \mathrm{kg}{ }^{-1}$ soil and half of them received no Se. Thus, the experiment contained four controls: 1) untreated soil without Se addition, 2) soil amended with stem residues or 3 ) leaf materials produced without Se fertilization, and 4) autoclaved soil without Se addition. 
N. Ebrahimi et al. (2015) 24: 104-117

The greenhouse pots with and without Se treatment were placed in separate rooms with identical growing conditions ( $16 / 8 \mathrm{~h}$ day/night, $60 \%$ humidity and $22 / 18^{\circ} \mathrm{C}$ day/night temperatures) to avoid cross-contamination by gaseous Se compounds during growth in the greenhouse. After germination, the plants were thinned to one seedling per pot and supplied twice (immediately after germination and at the flowering phase) with $10 \mathrm{ml}$ of a nutrient solution with the following composition: $\mathrm{NH}_{4} \mathrm{NO}_{3} 222.9 \mathrm{mM}, \mathrm{KH}_{2} \mathrm{PO}_{4} 67.1 \mathrm{mM}, \mathrm{MgSO}_{4} 65.0 \mathrm{mM}, \mathrm{CaHPO}{ }_{4} 50.3 \mathrm{mM}$, $\mathrm{H}_{3} \mathrm{BO}_{3} 9.6 \mathrm{mM}, \mathrm{MnCl}_{2} 4.7 \mathrm{mM}$, FeEDTA $3.7 \mathrm{mM}, \mathrm{ZnCl}, 1.6 \mathrm{mM}, \mathrm{Ni}\left(\mathrm{NO}_{3}\right)_{2} 0.9 \mathrm{mM}, \mathrm{CuSO}_{4} 0.8 \mathrm{mM}$ and $\left(\mathrm{NH}_{4}\right)_{6} \mathrm{Mo}_{7} \mathrm{O}_{24}$ $0.5 \mathrm{mM}$. The final nutrient concentrations in the added solution were (mM) N 450.7, Ca 50.3, K 67.1, Mg 65.1, P 117.4, S 65.8, B 9.6, Mn 4.7, Fe 3.7, Zn 1.6, Ni 0.9, Cu 0.8 and Mo 3.5.

The pots were placed in a completely randomized block design with four replications for each harvest time that corresponded to the four growth development stages according to the $\mathrm{BBCH}$ (Biologische Bundesanstalt, Bundessortenamt and Chemische Industrie) scale (Meier 2001): rosette (BBCH 16-19), bolting (BBCH 51-63), flowering (BBCH 75-78) and seed filling (BBCH 87-89). The photosynthesis rate $\left(\mu \mathrm{mol} \mathrm{m} \mathrm{m}^{-2} \mathrm{~s}^{-1}, \mathrm{LI}-6400, \mathrm{LI}-\mathrm{COR}\right)$ and leaf area $\left(\mathrm{cm}^{2}, \mathrm{LI} 3000 \mathrm{~A}\right.$, LI-COR) of youngest fully opened were measured before each harvest, and the chlorophyll contents of leaves were determined spectrophotometrically (UV-2100, Shimadzu) after extraction of the leaf samples with $80 \%$ acetone (Arnon 1949). Roots were carefully separated from the soil during each harvest. The fresh and subsequent dry weights of different plant parts were measured before and after drying at $70{ }^{\circ} \mathrm{C}$ for 48 hours. Three replicates were randomly selected for Se analysis by inductively coupled plasma atomic emission spectroscopy (ICP-OES) as described below.

\section{Determination of Se in plant samples}

Subsamples of 0.4-0.8 g of dried plant material were subjected to wet-ashing by being placed into glass tubes and incubated overnight at room temperature in $10 \mathrm{ml}$ of digestive acid mixture $\left(\mathrm{HNO}_{3}: \mathrm{H}_{2} \mathrm{SO}_{4}: \mathrm{HClO}_{4}, 6: 2: 3\right)$ and refluxed thereafter in a digester (2040 Digestor): $70{ }^{\circ} \mathrm{C}$ for $30 \mathrm{~min}, 120^{\circ} \mathrm{C}$ for $3 \mathrm{~h}, 160{ }^{\circ} \mathrm{C}$ for $30 \mathrm{~min}, 190{ }^{\circ} \mathrm{C}$ for 30 $\min$ and $220^{\circ} \mathrm{C}$ for $5 \mathrm{~h}$. The tubes were allowed to cool to room temperature, then $10 \mathrm{ml}$ of $12 \% \mathrm{HCl}$ was added and the mixture was boiled for $20 \mathrm{~min}$ at $130{ }^{\circ} \mathrm{C}$, then the volume was adjusted with distilled water to either 25 $\mathrm{ml}$ (zero and low Se) or $50 \mathrm{ml}$ (high Se). Each replicated sample was analysed in duplicate for Se by ICP-OES (iCPA 6000 Series, Thermo Scientific). Standard solutions were prepared from $\mathrm{Na}_{2} \mathrm{SeO}_{4}$ (Sigma, purum p.a., $\geq 98.0 \%$ (T)). Two wheat flour samples (Se concentrations 28 and $246 \mu \mathrm{gg}^{-1} \mathrm{DM}$ ) were used as in-house standards.

\section{Soil analyses \\ Electrical conductivity index and $\mathrm{pH}$}

A soil-water suspension $(1: 2.5 \mathrm{v} / \mathrm{v})$ was prepared and mixed by a glass rod, the flasks were covered with Parafilm ${ }^{\circledR}$ to minimize evaporation and incubated overnight. The electrical conductivity ( $\mathrm{mS} \mathrm{cm}^{-1}$, JENWAY 4020) and $\mathrm{pH}$ (Metrohm 744) of the solution were measured according to Hanlon (1993). The electrical conductivity was converted into a conductivity index to give a measure of the salinity of the soil solution as follows:

$$
\text { Conductivity index }=10\left(\mathrm{~cm} \mathrm{~ms}^{-1}\right) \times \text { Electrical conductivity }\left(\mathrm{ms} \mathrm{cm}^{-1}\right)
$$

\section{Soil respiration}

Three replicates for each soil sample for the two controls (untreated and autoclaved soils without added Se) and the corresponding soils that had been supplemented with inorganic Se ( $7 \mu \mathrm{g} \mathrm{Se} \mathrm{kg}{ }^{-1}$ soil) were stored at room temperature for one week before incubation for $\mathrm{CO}_{2}$ measurement. The water holding capacity (WHC) of the soil was determined according to standard methods of soil analysis (Grace et al. 2006). Thereafter $65 \mathrm{~g}$ of soil was taken from each sample $(60 \% \mathrm{WHC})$ was weighed into jars $(470 \mathrm{ml})$ with closed lids and incubated at $20^{\circ} \mathrm{C}$. Air samples were collected after $24 \mathrm{~h}$ into He-flushed and pre-evacuated vials and analysed by gas chromatography (5890 Series II, Hewlett Packard). A gas mixture with certified concentrations (Air Liquide) was used as the calibration standards, and room air as controls.

\section{Statistical analysis}

Data were grouped according to the four plant growth stages and analysed by using the one-way analysis of variance (ANOVA) and the comparison of means was performed by Tukey's test at $p \leq 0.05$. The data on the highest Se addition level differed drastically from the other treatments, therefore they were excluded from the statistical analysis and will be discussed separately. 


\section{Results \\ Plant growth and development}

The added inorganic Se slightly accelerated the phenological development of the plants at all growth stages (Table 1). Inorganic Se also increased the shoot DM at the bolting and flowering stages $(p \leq 0.05)$, whereas no significant effect on DM was found at the seed filling stage. Addition of inorganic Se significantly increased DM of the roots only at the bolting stage when the root DM was about three-fold higher than in the Se-supplied plants.

\section{The effects of autoclaving}

The autoclaved soil tended to increase the shoot DM at the bolting and flowering stages, but this effect was significant only for the control soil that had not been amended with Se (Table 1). Autoclaving of soil also enhanced the phenological development at the bolting stage of the plants. The inorganic Se added to non-autoclaved and autoclaved soil increased the shoot DM and enhanced the phenological development at the bolting and flowering stages. However, the relative increase in DM yield of the plants was smaller for the autoclaved soil treatment. Autoclaving the soil exerted no effect on root growth at any growth stage (Table 1).

\section{Inorganic vs. organic Se}

The soils treated by leaf and stem residues without enriched organic Se (0 $\mu \mathrm{g}$ Se kg-1 soil), showed an accumulation of shoot and root DM at all growth stages which was similar to the controls of the inorganic Se treatment. The only exception to this was the significantly higher root and shoot DM by the leaf residue addition at the flowering stage (Table 1). Plant development was accelerated by added organic Se at all harvests in broadly the same way as that obtained for inorganic Se. However, it was also noted that non-enriched leaf residues markedly accelerated plant development at the bolting stage. The Se-enriched stem residue addition significantly increased the shoot DM at the bolting stage, whereas the Se-enriched leaf residue treatment doubled the root DM, compared with the respective non-enriched controls. This response to Se disappeared at the later growth stages. Addition of stem-residue tended to have a slowing/inhibiting effect plant development and DM accumulation compared to inorganic Se treatment.

Table 1. Roots and shoots dry matter (DM, g plant ${ }^{-1}$ ) and phenological development expressed on the BBCH-scale at different growth stages of $B$. napus L. plants grown in soil treated with inorganic Se $\left(0,7\right.$ and $140 \mu \mathrm{g} \mathrm{kg}^{-1}$ soil), organic Se (leaf and stem residues, 0 and $7 \mu \mathrm{g} \mathrm{kg}^{-1}$ soil) and in autoclaved soil with inorganic Se (0 and $7 \mu \mathrm{gg}^{-1}$ soil)

\begin{tabular}{|c|c|c|c|c|c|c|c|c|c|c|c|c|}
\hline \multirow{3}{*}{$\begin{array}{l}\text { Se added } \\
\mu g \mathrm{~kg}^{-1} \text { soil }\end{array}$} & \multicolumn{3}{|c|}{ Rosette } & \multicolumn{3}{|c|}{ Bolting } & \multicolumn{3}{|c|}{ Flowering } & \multicolumn{3}{|c|}{ Seed filling } \\
\hline & Root & Shoot & $\begin{array}{l}\mathrm{BBCH} \\
\text { stage }\end{array}$ & Root & Shoot & $\begin{array}{l}\mathrm{BBCH} \\
\text { stage }\end{array}$ & Root & Shoot & $\begin{array}{l}\mathrm{BBCH} \\
\text { stage }\end{array}$ & Root & Shoot & $\begin{array}{l}\mathrm{BBCH} \\
\text { stage }\end{array}$ \\
\hline & DM & DM & & DM & DM & & DM & DM & & DM & DM & \\
\hline \multicolumn{13}{|l|}{ Inorganic Se } \\
\hline 0 & $0.24^{a}$ & $2.38^{a b c}$ & $15-16$ & $0.61^{d}$ & $6.94 \mathrm{de}$ & $50-52$ & $1.91^{c}$ & $11.13^{d}$ & $76-77$ & $10.12^{a}$ & $41.01^{a b}$ & $86-87$ \\
\hline 7 & $0.24^{\mathrm{a}}$ & $2.08^{b c}$ & $18-19$ & $2.11^{a b}$ & $10.84^{a b c}$ & $63-64$ & $2.90 \mathrm{abc}$ & $15.76^{a b}$ & $78-79$ & $8.55^{a}$ & $38.55^{a b}$ & $88-89$ \\
\hline$(140)^{*}$ & 0.23 & 2.60 & 19 & 1.69 & 10.6 & $60-63$ & 2.80 & 15.3 & $77-78$ & 8.5 & 44.3 & $87-89$ \\
\hline \multicolumn{13}{|c|}{ Autoclaved soils } \\
\hline 0 & $0.40^{a}$ & $3.72^{\mathrm{a}}$ & 16 & $0.76^{d}$ & $10.13^{b c}$ & $57-58$ & $2.39 a b c$ & $15.40^{b}$ & 77 & $9.62^{a}$ & $41.42^{a b}$ & 88 \\
\hline 7 & $0.36^{a}$ & $3.38^{a b}$ & 17-19 & $1.93^{b c}$ & $12.93^{a}$ & 63 & $2.11^{b c}$ & $19.14^{\mathrm{a}}$ & 77-78 & $8.27^{a}$ & $42.01^{a}$ & $88-89$ \\
\hline \multicolumn{13}{|l|}{ Leaf residues } \\
\hline 0 & $0.20^{a}$ & $2.82 \mathrm{abc}$ & $16-17$ & $1.50 \mathrm{bcd}$ & 9.64 bcd & $61-62$ & $3.56^{a}$ & $14.89 \mathrm{bc}$ & $76-78$ & $9.81^{a}$ & $41.38^{a b}$ & 88 \\
\hline 7 & $0.34^{\mathrm{a}}$ & $3.72^{a}$ & 19 & $3.02^{\mathrm{a}}$ & $11.74^{\mathrm{ab}}$ & $61-63$ & $3.27^{\mathrm{ab}}$ & $18.42^{\mathrm{ab}}$ & 78-79 & $9.68^{a}$ & $42.43^{a}$ & $88-89$ \\
\hline \multicolumn{13}{|l|}{ Stem residues } \\
\hline 0 & $0.27^{a}$ & $1.70^{c}$ & $14-16$ & $0.88^{\mathrm{cd}}$ & $5.54^{\mathrm{e}}$ & 55 & $2.38^{a b c}$ & $10.36^{d}$ & 75 & $7.83^{a}$ & $34.21^{b}$ & 87 \\
\hline 7 & $0.21^{a}$ & $2.20^{b c}$ & $16-18$ & $1.55^{\mathrm{bcd}}$ & $8.62^{\mathrm{cd}}$ & $60-62$ & $2.44 \mathrm{abc}$ & $11.78^{c d}$ & $76-77$ & $8.65^{a}$ & $38.05^{a b}$ & $87-89$ \\
\hline SE & 0.11 & 0.40 & & 0.32 & 0.84 & & 0.38 & 1.07 & & 0.90 & 2.27 & \\
\hline
\end{tabular}

Data are expressed in means $\pm S E, n=4$.

Values in each column followed by the same letters are not significantly different at $p \leq 0.05$.

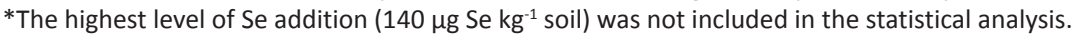


N. Ebrahimi et al. (2015) 24: 104-117

The growth-promoting effect of Se was also reflected as an increasing trend in the weight of the silique walls, even if it was not statistically significant $(p \leq 0.05)$ (Fig. 1). The DM yield of seeds increased as a response to all Se forms

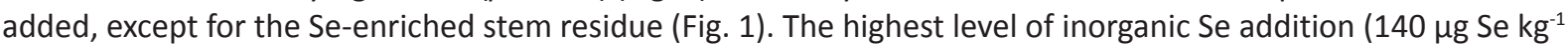
soil) increased the shoot DM at all growth stages, and the DM of silique walls and seeds. The positive effect of Se on the root DM was observed at the bolting and flowering stages (Table 1 and Fig. 1).

\section{$\square$ Seed $\square$ Silique wall}

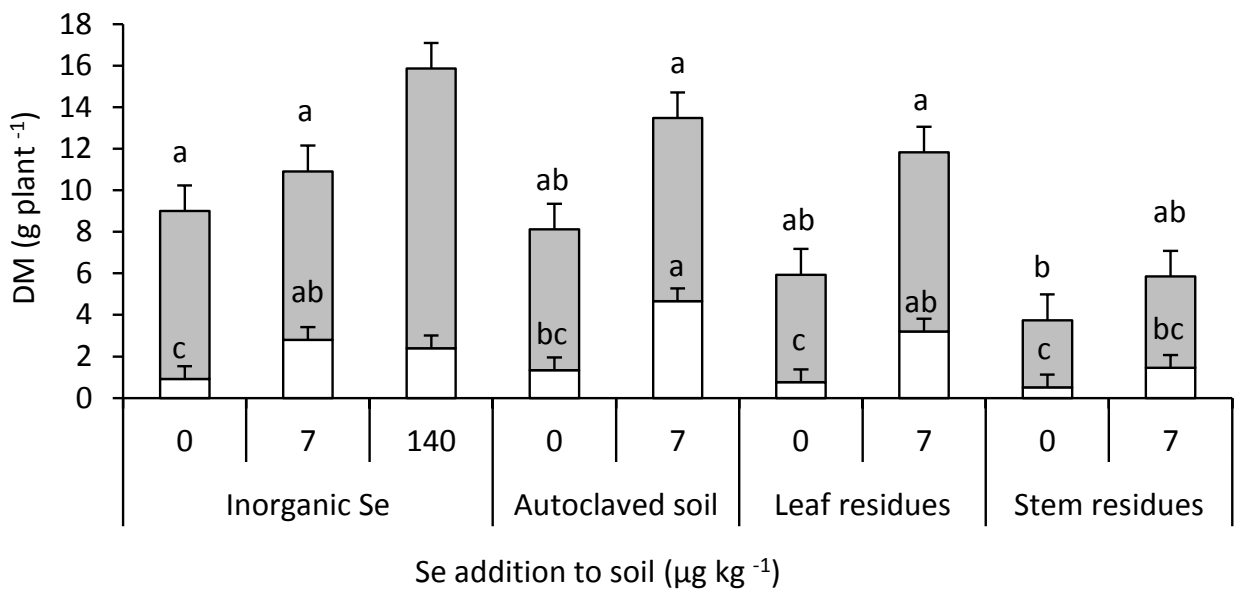

Fig.1. Dry matter (g plant ${ }^{-1}$ ) of seeds and the silique walls of $B$. napus $\mathrm{L}$. plants at the seed filling stage grown in soil treated with inorganic Se $\left(0,7\right.$ and $140 \mu \mathrm{gg}^{-1}$ soil), organic Se (leaf and stem residue, 0 and $7 \mathrm{\mu g} \mathrm{kg}^{-1}$ soil) and in autoclaved soil with inorganic Se ( 0 and $7 \mu \mathrm{gg}^{-1}$ soil). Data are expressed as means $\pm \mathrm{SE}, n=4$. The same letter indicates no significant difference among the error bars with the same shading, at $p \leq 0.05$. The highest level of Se addition ( $140 \mu \mathrm{g} \mathrm{kg}^{-1}$ soil) was not included in this statistical analysis.

\section{Photosynthesis and chlorophyll content}

The photosynthesis rates peaked at the rosette and flowering stages (Table 2). Photosynthesis at the rosette stage was significantly enhanced by the inorganic Se and Se-enriched stem residues. Only the Se-supplied plants that were grown in the autoclaved soil showed a slight but not statistically significant increase in photosynthesis rates $(p \leq 0.05)$ (Table 2$)$ at the bolting stage. However, no Se-induced increases were found for the stomatal conductivity and for the water use efficiency (WUE) at this stage.

Table 2. Photosynthesis rates $\left(\mathrm{A}, \mu \mathrm{mol} \mathrm{m} \mathrm{m}^{-2} \mathrm{~s}^{-1}\right)$, stomatal conductivities $\left(\mathrm{g}_{\mathrm{s}^{\prime}} \mathrm{mol} \mathrm{m}^{-2} \mathrm{~s}^{-1}\right)$ and water use efficiency (WUE) values of $B$. napus L. plants grown in soil treated with inorganic Se $\left(0,7\right.$ and $140 \mu \mathrm{gg}^{-1}$ soil), organic Se (leaf and stem residue, 0 and $7 \mu \mathrm{g} \mathrm{kg}{ }^{-1}$ soil) and in autoclaved soil with inorganic Se ( 0 and $7 \mathrm{\mu g} \mathrm{kg}^{-1}$ soil) at different growth stages

\begin{tabular}{|c|c|c|c|c|c|c|c|c|c|c|c|c|}
\hline \multirow{2}{*}{$\begin{array}{l}\text { Se added } \\
\left(\mu \mathrm{kg}^{-1} \text { soil) }\right.\end{array}$} & \multicolumn{3}{|c|}{ Rosette } & \multicolumn{3}{|c|}{ Bolting } & \multicolumn{3}{|c|}{ Flowering } & \multicolumn{3}{|c|}{ Seed filling } \\
\hline & A & $g_{s}$ & WUE & A & $g_{s}$ & WUE & A & $g_{s}$ & WUE & A & $g_{s}$ & WUE \\
\hline \multicolumn{13}{|l|}{ Inorganic Se } \\
\hline 0 & $12.75^{\mathrm{c}}$ & $0.46^{\mathrm{a}}$ & $3.18^{a}$ & $9.37^{a b}$ & $0.24^{a}$ & $3.11^{\mathrm{a}}$ & $12.48^{a}$ & $0.31^{b}$ & $3.05^{\mathrm{a}}$ & $5.97^{\mathrm{a}}$ & $0.26^{a}$ & $1.82^{\mathrm{a}}$ \\
\hline 7 & $15.65^{a b}$ & $0.62^{\mathrm{a}}$ & $3.27^{\mathrm{a}}$ & $10.87^{\mathrm{ab}}$ & $0.34^{\mathrm{a}}$ & $2.51^{\mathrm{a}}$ & $15.00^{\mathrm{a}}$ & $0.42^{a b}$ & $2.59^{\mathrm{a}}$ & $\mathrm{nm}$ & $\mathrm{nm}$ & $\mathrm{nm}$ \\
\hline$(140)^{*}$ & $(14.8)$ & $(0.64)$ & (2.97) & $(12.6)$ & $(0.36)$ & (2.79) & $(15.8)$ & $(0.68)$ & (2.04) & $(4.4)$ & (0.14) & (2.41) \\
\hline \multicolumn{13}{|c|}{ Autoclaved soil } \\
\hline 0 & $13.58^{b c}$ & $0.42^{\mathrm{a}}$ & $3.60^{\mathrm{a}}$ & $8.34^{b}$ & $0.43^{a}$ & $2.71^{\mathrm{a}}$ & $12.63^{a}$ & $0.57^{a b}$ & $1.91^{\mathrm{a}}$ & $\mathrm{nm}$ & $\mathrm{nm}$ & $\mathrm{nm}$ \\
\hline 7 & $15.40 \mathrm{abc}$ & $0.63^{a}$ & $3.11^{\mathrm{a}}$ & $13.18^{a}$ & $0.62^{a}$ & $2.42^{\mathrm{a}}$ & $15.10^{a}$ & $0.53^{a b}$ & $2.03^{a}$ & $\mathrm{~nm}$ & $\mathrm{~nm}$ & $\mathrm{~nm}$ \\
\hline \multicolumn{13}{|l|}{ Leaf residues } \\
\hline 0 & $13.05^{b c}$ & $0.53^{a}$ & $3.17^{\mathrm{a}}$ & $11.18^{a b}$ & $0.40^{a}$ & $2.75^{\mathrm{a}}$ & $12.95^{a}$ & $0.49^{a b}$ & $2.16^{a}$ & $5.33^{\mathrm{a}}$ & $0.22^{\mathrm{a}}$ & $1.73^{a}$ \\
\hline 7 & $14.53 \mathrm{abc}$ & $0.49^{a}$ & $3.56^{a}$ & $12.23 \mathrm{ab}$ & $0.53^{a}$ & $2.30^{a}$ & $15.03^{a}$ & $0.47^{a b}$ & $2.29^{a}$ & $5.63^{a}$ & $0.14^{a}$ & $2.55^{a}$ \\
\hline \multicolumn{13}{|l|}{ Stem residues } \\
\hline 0 & $13.13^{b c}$ & $0.51^{\mathrm{a}}$ & $3.09^{a}$ & $11.33 \mathrm{ab}$ & $0.69^{a}$ & $2.21^{\mathrm{a}}$ & $13.98^{\mathrm{a}}$ & 0.54 ab & $2.17^{\mathrm{a}}$ & $6.55^{\mathrm{a}}$ & $0.22^{\mathrm{a}}$ & $2.08^{a}$ \\
\hline 7 & $16.03^{a}$ & $0.71^{a}$ & $3.15^{\mathrm{a}}$ & $12.75^{a}$ & $0.61^{a}$ & $2.24^{\mathrm{a}}$ & $15.23^{a}$ & $0.76^{a}$ & $1.87^{\mathrm{a}}$ & $5.47^{\mathrm{a}}$ & $0.16^{a}$ & $2.23^{a}$ \\
\hline SE & 0.81 & 0.09 & 0.38 & 1.29 & 0.14 & 0.27 & 1.00 & 0.11 & 0.38 & 0.79 & 0.06 & 0.38 \\
\hline
\end{tabular}

Data are expressed as means $\pm \mathrm{SE}, n=4$.

Values in each column that are marked by the same letters are not significantly different at $p \leq 0.05$.

nm: no measurement

*The highest level of Se addition was not included in the statistical analysis. 
There were no significant differences in chlorophyll $a$ and $b$ contents between the Se-treated and control plants at the rosette, flowering and seed filling stages. However, the chlorophyll $a$ significantly diminished at the bolting stage in the plants supplied with organic Se and also in the autoclaved soil treated with inorganic Se $(p \leq 0.05)$ (Fig. 2). The decline in chlorophyll $b$ was significant only in the plants treated by Se-enriched leaf residues $(p \leq 0.05)$ (Fig. 2). The highest Se addition ( $140 \mu \mathrm{g} \mathrm{kg}{ }^{-1}$ ) elevated the chlorophyll $a$ and $b$ content at all growth stages as compared to the control. This agrees with the increased photosynthesis rates and stomatal conductivity recorded at all growth stages except the seed filling stage (Table 2).

\section{Se concentration in plant tissue}

The highest inorganic Se dosage (140 $\mathrm{g} \mathrm{kg}^{-1}$ soil) resulted in drastically high Se concentrations in plant tissues at all growth stages (Tables 3-6). The concentrations of Se in the roots in this treatment when the plant was at the rosette stage ranged from 15- to143-fold those of the Se concentrations in plant roots of the other treatments. The corresponding elevation of Se in the shoots was 17-508-fold for the highest inorganic Se dosage. This concentration difference in the root Se gradually diminished over time.

\begin{tabular}{|c|c|c|}
\hline \multirow{2}{*}{$\begin{array}{c}\text { Se added } \\
\text { ( } \mu \mathrm{g} \mathrm{kg} \mathrm{kg}^{-1} \text { soil) }\end{array}$} & \multicolumn{2}{|c|}{ Se concentration ( $\mu \mathrm{g} \mathrm{g}^{-1} \mathrm{DW}$ ) at rosette stage } \\
\hline & Roots & Shoots \\
\hline \multicolumn{3}{|l|}{ Inorganic Se } \\
\hline 0 & $0.018^{c}$ & $0.009^{c}$ \\
\hline 7 & $0.764^{a}$ & $0.527^{a b}$ \\
\hline$(140)^{*}$ & (11.804) & (13.737) \\
\hline \multicolumn{3}{|l|}{ Autoclaved soil } \\
\hline 0 & $0.023^{c}$ & $0.010^{c}$ \\
\hline 7 & $0.732^{a}$ & 0.799 a \\
\hline \multicolumn{3}{|l|}{ Leaf residues } \\
\hline 0 & $0.037^{c}$ & $0.004^{c}$ \\
\hline 7 & $0.221^{b}$ & $0.132 \mathrm{bc}$ \\
\hline \multicolumn{3}{|l|}{ Stem residues } \\
\hline 0 & $0.020^{c}$ & $0.010^{c}$ \\
\hline 7 & $0.082^{c}$ & $0.027^{c}$ \\
\hline SE & 0.034 & 0.135 \\
\hline
\end{tabular}

\section{Rosette stage}

The addition of inorganic Se elevated the concentration of Se in the roots and shoots at the rosette stage more efficiently than did the organic Se forms (Table 3). Interestingly, this response was more pronounced (1.5-fold increase) in the shoots of $B$. napus L. plants grown in the autoclaved soil than that in the non-autoclaved soil. No such difference was found in the roots. The organic Se forms differed in their efficiency: the Se that was added by the leaf material produced higher Se concentrations in both roots and shoots, whereas the impact of Se added by the stem material did not significantly affect the concentrations of Se in treated plants.

\section{Bolting stage}

The inorganic Se, significantly increased the concentrations in the roots, stems and leaves both in non-autoclaved and autoclaved soil $(p \leq 0.05)$ at the bolting stage compared to the organic Se treatments and their corresponding controls (Table 4). Inorganic Se added to the autoclaved soil elevated the Se concentration of leaves more than the same amount added to the non-autoclaved soil. Organic Se added as leaf residue elevated the concentration in the leaves of growing oilseed plants but Se added as stem residue material did not have any effect. Interestingly, the leaf residue control produced the highest concentration of Se in the root controls (Table 4). 
N. Ebrahimi et al. (2015) 24: 104-117

Table 4. Se concentrations ( $\mu \mathrm{g} \mathrm{g}^{-1} \mathrm{DM}$ ) in roots, stems and leaves of $B$. napus $\mathrm{L}$. plants grown in soils treated with inorganic Se $\left(0,7\right.$ and $140 \mu \mathrm{g} \mathrm{kg}^{-1}$ soil), organic Se (leaf and stem residues, 0 and $7 \mu \mathrm{gg}^{-1}$ soil) and in autoclaved soils with inorganic Se ( 0 and $7 \mathrm{\mu g} \mathrm{kg}^{-1}$ soil) at the bolting stage

\begin{tabular}{|c|c|c|c|}
\hline \multirow{2}{*}{ Se added ( $\mu \mathrm{g} \mathrm{kg}^{-1}$ soil) } & \multicolumn{3}{|c|}{ Se concentration ( $\mu \mathrm{g} \mathrm{g}^{-1} \mathrm{DW}$ ) at bolting stage } \\
\hline & Roots & Stems & Leaves \\
\hline \multicolumn{4}{|l|}{ Inorganic Se } \\
\hline 0 & $0.025^{b c}$ & $0.009^{b}$ & $0.020^{\mathrm{cd}}$ \\
\hline 7 & $0.057^{\mathrm{a}}$ & $0.363^{a}$ & $0.603^{b}$ \\
\hline$(140)^{*}$ & (4.029) & (5.127) & (12.589) \\
\hline \multicolumn{4}{|l|}{ Autoclaved soil } \\
\hline 0 & $0.030^{b}$ & $0.008^{b}$ & $0.010^{d}$ \\
\hline 7 & $0.062^{\text {a }}$ & $0.234^{\mathrm{a}}$ & $0.794^{a}$ \\
\hline \multicolumn{4}{|l|}{ Leaf residues } \\
\hline 0 & $0.066^{a}$ & $0.004^{b}$ & $0.002^{d}$ \\
\hline 7 & $0.032^{b}$ & $0.032^{b}$ & $0.095^{c}$ \\
\hline \multicolumn{4}{|l|}{ Stem residues } \\
\hline 0 & $0.004^{c}$ & $0.015^{b}$ & $0.013^{d}$ \\
\hline 7 & $0.018^{b c}$ & $0.026^{b}$ & $0.020^{\mathrm{cd}}$ \\
\hline SE & 0.006 & 0.046 & 0.024 \\
\hline
\end{tabular}

Data are given as means $\pm S E, n=3$

The same letters indicate no significant difference within columns, at $p \leq 0.05$.

*The highest level of Se addition was not included in the statistical analysis.

\section{Flowering stage}

Organic Se applied as the stem residue material failed to increase the Se concentration in stems, leaves or the siliques at the flowering stage but increased Se concentrations significantly in the roots $(p \leq 0.05)$ (Table 5). Once again, inorganic Se was found to be superior to organic forms of Se at increasing Se in various plant parts $(p \leq 0.05)$. The addition of inorganic Se also increased the Se content of the siliques more in the autoclaved soil (maximum $0.085 \mathrm{\mu g} \mathrm{g}^{-1} \mathrm{DM}$ ) than in the non-autoclaved soil (maximum $0.074 \mu \mathrm{g} \mathrm{g}^{-1} \mathrm{DM}$ ) (Table 5).

Table 5. Se concentration ( $\mu \mathrm{g} \mathrm{g}^{-1} \mathrm{DM}$ in root, stem, leaves and the siliques of $B$. napus $\mathrm{L}$. plants grown in soils treated with inorganic Se $\left(0,7\right.$ and $140 \mathrm{\mu g} \mathrm{kg}^{-1}$ soil), organic Se (leaf and stem residue, 0 and $7 \mathrm{\mu g} \mathrm{kg}^{-1}$ soil) and in autoclaved soil with inorganic Se ( 0 and $7 \mathrm{~g} \mathrm{~kg}^{-1}$ soil) at the flowering stage.

\begin{tabular}{|c|c|c|c|c|}
\hline \multirow{2}{*}{$\begin{array}{l}\text { Se added } \\
\text { ( } \mu \mathrm{kg}^{-1} \text { soil) }\end{array}$} & \multicolumn{4}{|c|}{ Se concentrations ( $\mu \mathrm{g} \mathrm{g}^{-1} \mathrm{DW}$ ) at flowering stage } \\
\hline & Roots & Stems & Leaves & Siliques \\
\hline \multicolumn{5}{|l|}{ Inorganic Se } \\
\hline 0 & $0.030^{d}$ & $0.049^{c}$ & $0.016^{\mathrm{b}}$ & $0.013^{c}$ \\
\hline 7 & $0.296^{a}$ & $0.129^{a}$ & $0.646^{a}$ & $0.074^{b}$ \\
\hline$(140)^{*}$ & (2.858) & (2.951) & (9.471) & $(1.380)$ \\
\hline \multicolumn{5}{|l|}{ Autoclaved soil } \\
\hline 0 & $0.061^{c d}$ & $0.010^{d}$ & $0.014^{b}$ & $0.001^{d}$ \\
\hline 7 & $0.290^{\mathrm{a}}$ & $0.162^{\mathrm{a}}$ & $0.741^{\mathrm{a}}$ & $0.085^{a}$ \\
\hline \multicolumn{5}{|l|}{ Leaf residues } \\
\hline 0 & $0.060^{c d}$ & $0.008^{d}$ & $0.002^{b}$ & $0.001^{d}$ \\
\hline 7 & $0.155^{b}$ & $0.017^{d}$ & $0.107^{\mathrm{b}}$ & $0.008^{c}$ \\
\hline \multicolumn{5}{|l|}{ Stem residues } \\
\hline 0 & $0.051^{d}$ & $0.002^{d}$ & $0.004^{b}$ & $0.001^{d}$ \\
\hline 7 & $0.105^{c}$ & $0.001^{d}$ & $0.004^{b}$ & $0.001^{d}$ \\
\hline SE & 0.014 & 0.008 & 0.033 & 0.003 \\
\hline
\end{tabular}

Data are given as means $\pm S E, n=3$.

The same letters indicate no significant difference within columns, at $p \leq 0.05$.

*The highest level of Se addition was not included in the statistical analysis. 
Rosette

$\square$ Chla $\square$ Chlb

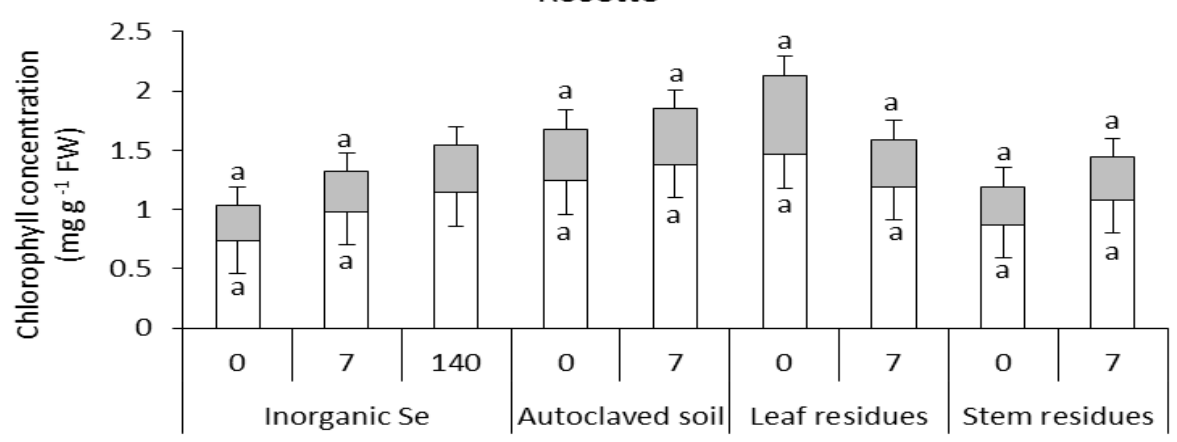

Se addition to soil $\left(\mu \mathrm{gg}^{-1}\right)$

Bolting

$\square$ Chla $\square$ Chlb

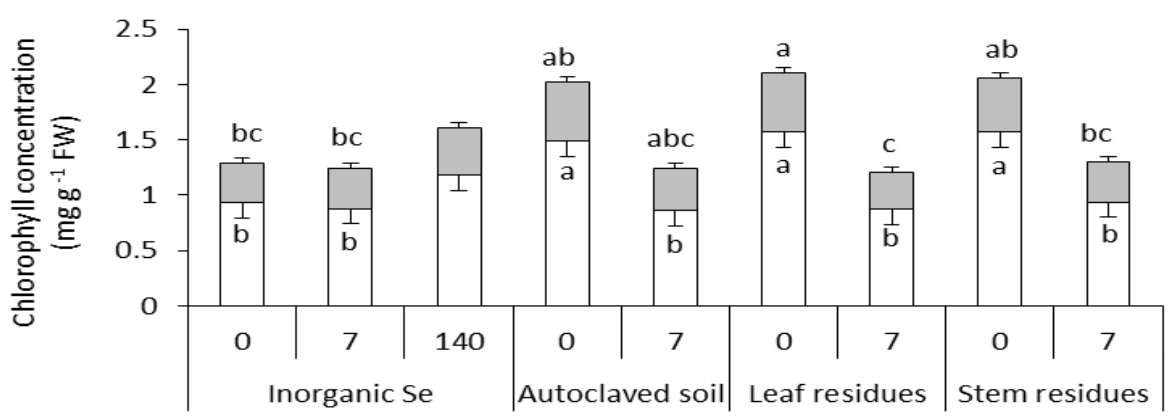

Se addition to soil $\left(\mu \mathrm{g} \mathrm{e}^{-1}\right)$

Flowering

$\square$ Chla $\square$ Chlb

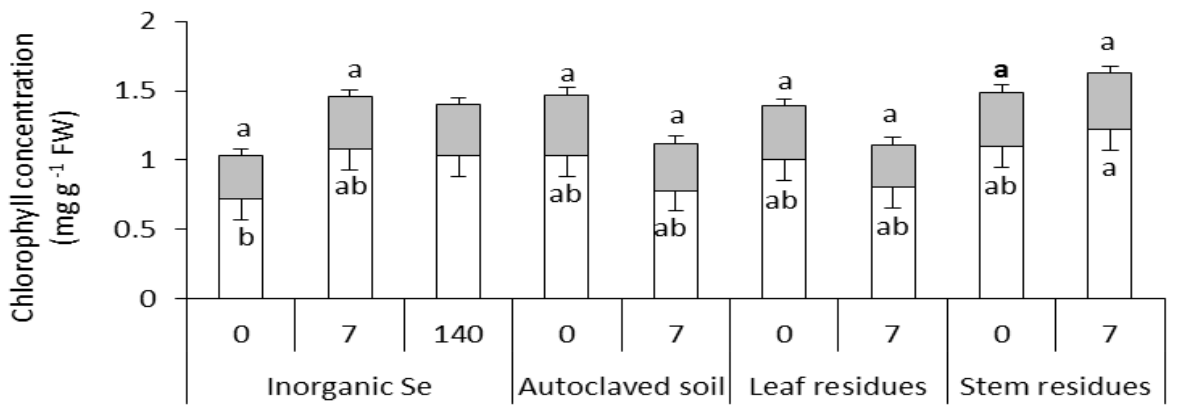

Se addition to soil $\left(\mu \mathrm{gg}^{-1}\right)$

Seed filling

$\square$ Chla $\square$ Chlb

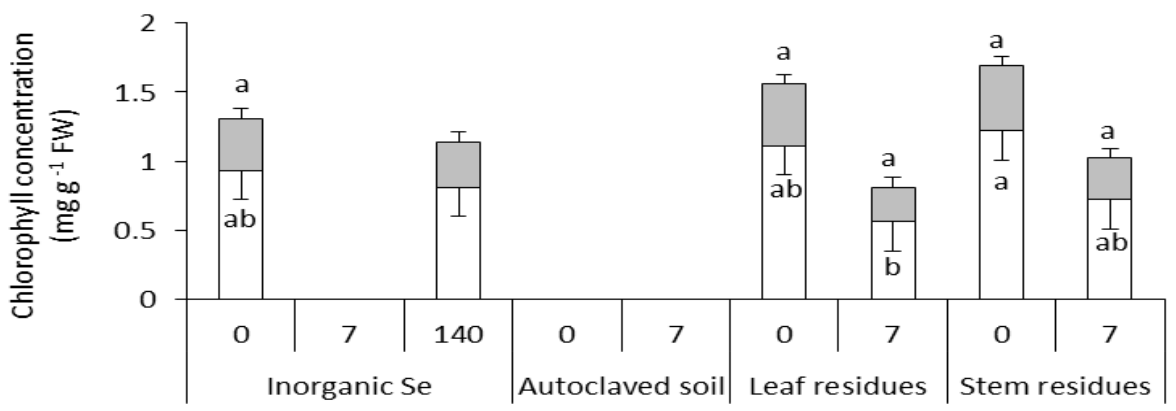

Se addition to soil $\left(\mu \mathrm{gg}^{-1}\right)$

Fig. 2. Chlorophyll $a$ and $b$ (Chl $a$ and $b \mathrm{mg} \mathrm{g}^{-1} \mathrm{FW}$ leaf) concentrations in leaves of $B$. napus L. plants that were grown in soil treated with inorganic Se $\left(0,7\right.$ and $140 \mu \mathrm{g} \mathrm{kg}^{-1}$ soil), organic Se (leaf and stem residue, 0 and $7 \mu \mathrm{g} \mathrm{kg}^{-1}$ soil) and in autoclaved soil with inorganic Se ( 0 and $7 \mu \mathrm{g} \mathrm{kg}^{-1}$ soil) at different growth development stages. Data are given in means $\pm S E, n=4$. The same letter indicates no significant difference among bars with same colour, at $p \leq 0.05$. The highest level of Se addition was not included in statistical analysis 
N. Ebrahimi et al. (2015) 24: 104-117

Seed filling stage

The inorganic Se treatments resulted in significantly increased Se concentrations in all plant parts (root, stem, leaves and siliques) at the seed filling stage both in the autoclaved and non-autoclaved soils $(p \leq 0.05)($ Table 6$)$. The Se-enriched leaf residue exerted a significant increase in Se in all above-ground plant parts $(p \leq 0.05)$ (Table 6). The Se-enriched stem residue treatment significantly elevated Se in the siliques at this growth stage $(p \leq 0.05)$. Interestingly, the addition of $7.0 \mu \mathrm{g}$ of inorganic Se $\mathrm{kg}^{-1}$ to the autoclacved soil produced the highest concentration of Se (1.5-fold that of non-autoclaved soil) in the siliques of growing plants $(p \leq 0.05)$. All plant parts of the plant that had been fertilized with organic Se-enriched materials had lower Se concentrations than their inorganic Se supplemented counterparts. The concentration of Se in the roots and stems for the Se-enriched stem residual treatment was below those in the corresponding controls (Table 6). The two organic Se forms had no discernible effect on the concentration of Se in the siliques.

Table 6. Se concentrations ( $\left.\mu \mathrm{g} \mathrm{g}^{-1} \mathrm{DM}\right)$ in roots, stems, leaves and the siliques of $B$. napus L. plants grown in soil treated with inorganic Se (0, 7 and $140 \mu \mathrm{gg}^{-1}$ soil), organic Se (leaf and stem residue, 0 and $7 \mu \mathrm{kg}^{-1}$ soil) and in autoclaved soil with inorganic Se ( 0 and $7 \mu \mathrm{kg}^{-1}$ soil) at the seed filling stage

\begin{tabular}{|c|c|c|c|c|}
\hline \multirow{2}{*}{$\begin{array}{c}\text { Se added } \\
\left(\mu \mathrm{g} \mathrm{kg}{ }^{-1} \text { soil }\right)\end{array}$} & \multicolumn{4}{|c|}{ Se concentrations ( $\left.\mu \mathrm{g} \mathrm{g}^{-1} \mathrm{DW}\right)$ at seed filling stage } \\
\hline & Root & Stem & Leaves & Siliques \\
\hline \multicolumn{5}{|l|}{ Inorganic Se } \\
\hline 0 & $0.018^{b}$ & $0.030^{d}$ & $0.013^{c}$ & $0.018^{c d}$ \\
\hline 7 & $0.144^{a}$ & $0.129^{b}$ & $0.324^{a}$ & $0.240^{b}$ \\
\hline$(140)^{*}$ & $(1.400)$ & $(2.344)$ & (6.166) & (3.631) \\
\hline \multicolumn{5}{|l|}{ Autoclaved soil } \\
\hline 0 & $0.018^{b}$ & 0.019 de & $0.013^{c}$ & $0.027^{c d}$ \\
\hline 7 & $0.172^{a}$ & $0.155^{a}$ & nd & $0.372^{a}$ \\
\hline \multicolumn{5}{|l|}{ Leaf residues } \\
\hline 0 & $0.016^{b}$ & $0.021^{\text {de }}$ & $0.005^{c}$ & $0.005^{d}$ \\
\hline 7 & $0.002^{b}$ & $0.059^{c}$ & $0.141^{b}$ & $0.060^{c}$ \\
\hline \multicolumn{5}{|l|}{ Stem residues } \\
\hline 0 & $0.015^{b}$ & 0.015 de & $0.012^{c}$ & $0.002^{d}$ \\
\hline 7 & $0.001^{b}$ & $0.003^{e}$ & $0.016^{c}$ & $0.074^{c}$ \\
\hline SE & 0.012 & 0.007 & 0.012 & 0.007 \\
\hline
\end{tabular}

Data are given as means $\pm S E, n=3$.

The same letters indicate no significant difference within columns, at $p \leq 0.05, \mathrm{nd}=$ not determined because all leaves had dropped.

*The highest level of Se addition was not included in the statistical analysis.

The Se levels of the roots tended to decline when the plant development stage progressed from the rosette to the seed filling stage (Tables 3-6). The concentrations of Se in the roots and shoots were at the same level at the rosette stage. The highest accumulation of Se was recorded in the leaves at the bolting and flowering stages. The form in which Se was applied had a considerable effect on the level of accumulation of Se. The accumulation of Se was rapid and more extensive for inorganic Se than for organic Se treatments. The added Se seem to preferentially accumulate in the siliques at the seed filling stage, although high concentrations of Se were also found in the leaves.

\section{Microbial respiration, $\mathrm{pH}$ and electrical conductivity of the soil}

Autoclaving the soil slightly increased soil respiration when no Se was added to soil, and decreased it at the low ( $7 \mu \mathrm{g} \mathrm{kg}^{-1}$ soil) addition level of inorganic Se (Fig. 3). Correspondingly, Se tended to increase the respiration in nonautoclaved soil and to lower it in the autoclaved soil. None of these responses were statistically significant.

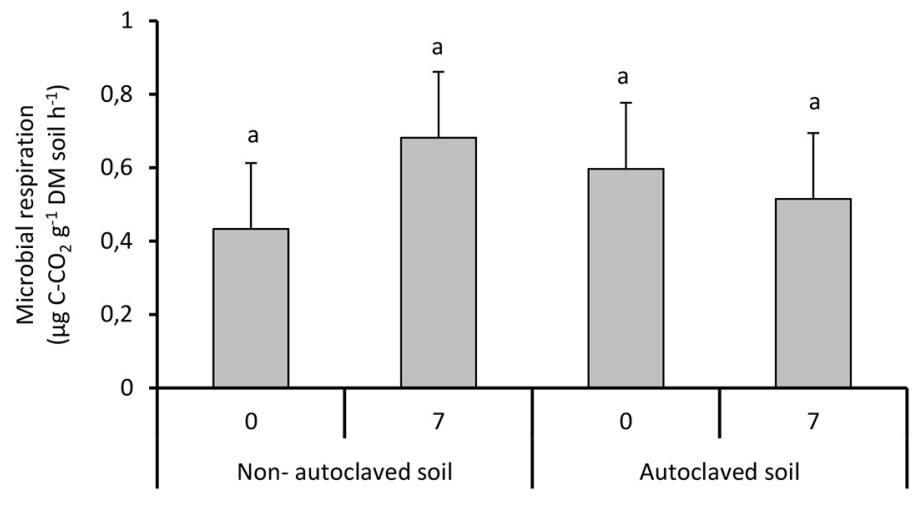

Se addition to soil $\left(\mu \mathrm{gg}^{-1}\right)$

Fig.3. Microbial respiration rates ( $\mu \mathrm{g} \mathrm{C}-\mathrm{CO}_{2} \mathrm{~g}^{-1} \mathrm{DM}$ soil $\mathrm{h}^{-1}$ ) in non-autoclaved or autoclaved soil with inorganic Se at 0 or $7 \mu \mathrm{gg}^{-1}$ after $24 \mathrm{~h}$ incubation. Soil samples were taken when the plants were at the rosette stage. Data are given in means $\pm S E, n=3$. The same letter indicates no significant difference among bars with same colour, at $p \leq 0.05$. 
At the rosette stage, the soil $\mathrm{pH}$ was equal in all treatments (Table 7). At the bolting stage, the treatment with the leaf residue not supplied with Se produced the highest $\mathrm{pH}$, but this response disappeared at the later growth stages. There were generally no significant differences between the various Se addition levels at any growth stage. Nevertheless, at the seed filling stage the soil pH in all treatments was about 0.5 unit lower than at the rosette stage. This was attributable to protons produced by the roots as response to cation uptake to maintain charge balance. Electrical conductivity index was highest at the rosette stage. A gradual decrease in the conductivity index upon with plant development can be explained by the nutrient uptake of plants lowering the free ions in the soil solution (Table 7). At the seed filling stage, the treatment with the leaf residue not enriched with Se had a significantly higher conductivity index than the other control treatments.

Table 7. Conductivity indices and pH of soil treated with inorganic Se (0, 7 and $140 \mu \mathrm{g} \mathrm{kg}^{-1}$ soil), organic Se (leaf and stem residue, 0 and $7 \mu \mathrm{g} \mathrm{Se} \mathrm{kg}{ }^{-1}$ soil) and autoclaved soil with inorganic Se ( 0 and $7 \mu \mathrm{gg}^{-1}$ soil) at the different growth stages

\begin{tabular}{|c|c|c|c|c|c|c|c|c|}
\hline \multirow{2}{*}{$\begin{array}{c}\text { Se added } \\
\text { ( } \mu \mathrm{g} \mathrm{kg} \mathrm{kg}^{-1} \text { soil) }\end{array}$} & \multicolumn{2}{|c|}{ Rosette } & \multicolumn{2}{|c|}{ Bolting } & \multicolumn{2}{|c|}{ Flowering } & \multicolumn{2}{|c|}{ Seed filling } \\
\hline & $\mathrm{pH}$ & $\begin{array}{c}\text { Conductivity } \\
\text { index }\end{array}$ & $\mathrm{pH}$ & $\begin{array}{c}\text { Conductivity } \\
\text { index }\end{array}$ & $\mathrm{pH}$ & $\begin{array}{c}\text { Conductivity } \\
\text { index }\end{array}$ & $\mathrm{pH}$ & $\begin{array}{c}\text { Conductivity } \\
\text { index }\end{array}$ \\
\hline \multicolumn{9}{|l|}{ Inorganic Se } \\
\hline 0 & $5.83^{b}$ & $3.36 \mathrm{abcd}$ & $5.79^{c}$ & $1.77^{b c}$ & $5.67^{d}$ & $1.18^{\mathrm{a}}$ & $5.38^{a b}$ & $0.75^{b c d}$ \\
\hline 7 & $5.94^{a b}$ & $1.93^{c}$ & $5.84^{b c}$ & $0.58^{c}$ & $5.67^{d}$ & $0.77^{a}$ & $5.20^{b}$ & $0.39^{d}$ \\
\hline$(140)^{*}$ & $(5.82)$ & $(2.23)$ & $(6.20)$ & (1.27) & (6.00) & $(1.02)$ & $(5.28)$ & $(0.60)$ \\
\hline \multicolumn{9}{|c|}{ Autoclaved soil } \\
\hline 0 & $5.96^{a b}$ & $3.82 \mathrm{abcd}$ & $5.88^{b c}$ & $0.67^{c d}$ & $5.78^{b c d}$ & $1.16^{a}$ & $5.32^{a b}$ & $0.51^{\mathrm{cd}}$ \\
\hline 7 & $5.89 a b$ & $3.41 \mathrm{abc}$ & $5.92^{b c}$ & $0.97^{c}$ & $5.93^{a b}$ & $0.68^{a}$ & $5.28^{a b}$ & $0.57^{c d}$ \\
\hline \multicolumn{9}{|l|}{ Leaf residues } \\
\hline 0 & $6.00^{a}$ & $4.95^{a b}$ & $6.21^{a}$ & $3.91^{a}$ & $5.97^{a}$ & $1.59^{a}$ & $5.47^{a}$ & $1.28^{a}$ \\
\hline 7 & $5.92^{a b}$ & $2.61^{\mathrm{bcd}}$ & $5.99 a b c$ & $0.60^{c d}$ & $5.88^{a b c}$ & $0.61^{a}$ & $5.27^{a b}$ & $0.51^{\mathrm{cd}}$ \\
\hline \multicolumn{9}{|l|}{ Stem residues } \\
\hline 0 & $5.77^{b}$ & $5.90^{a}$ & $6.04^{a b}$ & $0.96^{c d}$ & $5.74^{c d}$ & $0.51^{a}$ & $5.27^{a b}$ & $0.84^{b c}$ \\
\hline 7 & $5.93^{a b}$ & $4.74^{a b c}$ & $6.07^{a b}$ & $2.30^{b}$ & $5.91^{a b}$ & $1.30^{a}$ & $5.35^{a b}$ & $1.01^{\mathrm{ab}}$ \\
\hline SE & 0.06 & 0.90 & 0.07 & 0.39 & 0.05 & 0.37 & 0.07 & 0.13 \\
\hline
\end{tabular}

Data are expressed in means $\pm \mathrm{SE}, \mathrm{n}=4$.

Values in each column followed by the same letters are not significantly different from each other.

*Highest level of Se addition was not included in the statistical analysis.

\section{Discussion}

\section{The impact of the form of the added Se on the dynamics of dry mass accumulation and chlorophyll in plants}

The addition of Se to the soil exerted a dual effect on plant growth and development, depending on the form and dosage of the added Se. The addition of non-enriched and Se-enriched stem residues slightly decreased the total DM accumulation and seed yield as well as retarded the phenological development compared to the other treatments. These responses were not significantly associated with changes in soil pH or conductivity index. It is probable that low $\mathrm{C}: \mathrm{N}$ ratio in the stem residue increased the microbial immobilization of plant available nitrogen, which might contribute to poor plant growth at the rosette and flowering stages. Trinsourtrot et al. (2000) showed that soil incubation with $B$. napus $L$. residue led to rapid C-substrate decomposition, and immobilization of soil $\mathrm{N}$, which consequently reduced biomass accumulation and yield of Brassica napus L. On the contrary, in our study, the enrichment of soil by organic Se in form of stem residue reduced only slightly the DM yield of $B$. napus $L$.

Our study revealed that inorganic Se treatments accelerated the plant development and increased the DM of roots, shoots, siliques and seeds. There are several reports on the growth-promoting effect of low Se dosages in ryegrass and lettuce (Hartikainen and Xue 1999, Xue et al. 2001), potato (Turakainen et al. 2004) and Arabidopsis thaliana (White et al. 2004), and on higher seed production in Brassica rapa (Lyons et al. 2009). The positive effect of Se application on the growth and DM accumulation of plants found in the present study is supported by other studies on Brassica napus (Sharma et al. 2010), rootstocks of peach (Prunus persica L.) (Pezzarossa et al. 2009), and kenaf (Hibiscus cannabinus L.) (Srikanth Lavu et al. 2013). Moreover, Pezzarossa et al. (2009) reported an improved growth that continued up to the threshold of Se toxicity in soil $\left(2.5-5 \mathrm{mg} \mathrm{kg}^{-1}\right)$ was reached.

The improved growth found in our study was not associated with significant increases in photosynthesis or chlorophyll concentration. The Se-enriched leaf and stem residue as well as inorganic Se added to autoclaved soil concurrently decreased chlorophyll $a$ and increased plant growth at the bolting stage. Hawrylak-Nowak (2008) reported that Se treatment as selenate or selenomethionine (SeMet) decreased chlorophyll content in maize and this 
decrease was especially marked for the SeMet treatment. A study by Jain et al. (2015) found that the application of selenite reduced the chlorophyll content in sugarcane plants. The negative effect of Se on chlorophyll content may due to an inhibition of the pigment synthesis (Prasad and Prasad 1987). Moreover, an excess of Se can affect chlorophyll biosynthesis via its negative effect on porphobilinogen synthetase enzyme (Padmaja et al. 1989).

The role of Se in plant growth is not yet fully understood, and contradictory reports on its effects on chlorophyll content and also photosynthesis exist. Owusu-Sekyere et al. (2013) suggested that the increased soluble sugar and starch accumulation found in Se-treated alfalfa might be due to enhanced activity of 1,6 fructose bisphosphatase which is a key enzyme in carbon assimilation. Zhang et al. (2014) reported that the effect of an appropriate Se application ( $50 \mathrm{~g} \mathrm{Se} \mathrm{ha}^{-1}$ ) elevated the intracellular $\mathrm{CO}_{2}$ concentration, increased the photosynthesis rate and improved the protection of photosystem II in rice leaves. In studies with chicory (Cichorium intybus L.) (Germ et al. 2007) and lettuce (Hawrylak-Nowak 2013) Se is reported not to affect the chlorophyll content, whereas slight increases in chlorophyll content are found in Se-treated senescing lettuce (Xue et al. 2001), wheat (Triticum aestivum L. emend Thell.), B. napus L. (Sharma et al. 2010) and alfalfa (Owusu-Sekuyere et al. 2013). The experiments differed in the level of Se application, plant species and timing of the measurement of chlorophyll content and photosynthesis, which renders the interpretation of the results challenging. The results of the present study support those obtained in earlier ones on the growth-promoting effects of Se. The mechanisms behind observed results remain yet unsolved.

\section{The impact of the form of added Se on the dynamics of Se accumulation within plants}

The distribution of Se among different plant parts is known to vary with plant species, developmental stage and form of the applied Se (Terry et al. 2000). Our present study showed that the Se accumulation in the different parts of Brassica napus L. plant depends on the level of Se application, the form in which Se is applied and the plant growth stage. The results reveal that even when the organic Se form is returned to the soil in plant residues, it supplies the plants with potentially available forms of Se. However, such organic forms of Se are clearly less efficient at increasing the Se concentration in plants than is the inorganic selenate.

As expected, inorganic Se application efficiently elevated the Se concentration of plant tissues. Terry et al. (2000) reported that selenate is taken up in the root by a high-affinity sulfate transporter and was transported to the shoot faster than either selenite or an organic form of Se such as selenomethionine (SeMet). Similar results of an efficient accumulation of Se in Brassica as response to inorganic Se additions have been previously reported (Lyons et al. 2009, Seppänen et al. 2010 and Sharma et al. 2010). When added to soil, low levels of organic forms of Se are reported to be inferior to inorganic $\mathrm{Se}$, because the soil microorganisms use such organic forms as a $\mathrm{C}$ source (Eich-Greatorex et al. 2007). In our experiment the highest Se concentrations in the siliques were recorded in the plants grown in the autoclaved soil and also the other plant parts were significantly higher in Se than in the other treatments. This outcome suggests that a modest release of soil-bound Se occurred upon autoclavation. The low DM yields for the stem residue treatment can be taken to indicate that essential nutrients ( $\mathrm{N}$ or $\mathrm{P}$ ) were immobilized by the soil microbes during the degradation of residues that are high in carbon.

Microbial decomposition of organic matter can produce volatile organic Se forms that escape to the atmosphere, which lowers the plant-available Se reserves in the soil. Baziramakenga and Simard (1998) concluded that the decomposition of organic matter (plant residues or animal manure) releases low molecular weight organic acids which affect the nutrient bioavailability. The Se concentrations in various parts of plants grown in soil treated with Se-enriched leaf residues was higher than in those supplied with stem-bound Se of plants. This outcome can be attributable to the faster microbiological degradation of leaves that allows a more rapid Se uptake by plants. Kikkert and Berkelaar (2013) showed that in hydroponics an organic form of Se (SeMet) was taken up and translocated from root into shoot to a greater extent than selenate. Nevertheless, these authors also pointed out that in the soil solution the conditions can be different than those in hydroponics where the adsorption of Se anions onto soil particles and microbial activity are excluded.

The reduction of Se concentration in the roots at the bolting stage can be attributable to the translocation of the absorbed Se to the other parts such as stems and leaves in addition to a dilution effect caused by the increased biomass. The Se accumulated at similar levels in the roots and shoots at the vegetative stage, whereas the concentrations were highest in the leaves and eventually in the siliques during the reproductive growth stages. These results agree with the results of an earlier study by Terry et al. (2000). Those authors reported that at the early vegetative phase, most Se was found in the young leaves, but at the reproductive phase the Se content increased in the seeds and decreased in leaves, stems and roots. Our study showed that the organic forms of applied Se were inefficient at accumulating Se in the siliques. In other words, organic Se addition to soils caused the siliques of Brassica napus $\mathrm{L}$. to be that were lower in Se content than those produced by the corresponding amount of inorganic Se. 


\section{Conclusions}

The present study investigated the effects of inorganic and organic (leaf and stem residues) forms of Se supplementation on the dynamics of plant growth and Se accumulation in Brassica napus L., a species that is considered to be a Se-indicator. The results showed that both inorganic and organic forms of Se can slightly improve plant growth, unless the organic Se is given in the form of a stem residue. Accumulation of Se in the plant from the inorganic source $\left(\mathrm{Na}_{2} \mathrm{SeO}_{4}\right)$ was much higher than that from Se-enriched plant residues, especially that of the stem residue. When the plants supplied with inorganic Se grew in the autoclaved soil, their siliques were significantly higher in Se than those of the plants grown in the non-autoclaved soil. This outcome suggests that autoclaving enhanced the Se uptake from soil. The dynamics of Se concentrations for the inorganic Se treatments showed that during the vegetative phase Se accumulates in leaves, whereas at the reproductive phase the Se in the siliques starts to increase, and Se in other plant parts decrease. The addition of Se-enriched plant residues (particularly in the form of stem residue) caused no significant change in the Se accumulation in plants until the seed filling stage. The present results carried out under greenhouse conditions that are likely to favour high rates of Se mineralization suggest that organic Se forms are not as effective as inorganic selenate in increasing the Se concentration of plant tissues. Much higher amounts of Se-enriched plant residues would be needed for similar increases in the plant Se contents, thus the use of inorganic forms of Se are still preferred for biofortification programs.

\section{Acknowledgments}

This research was financially supported by the Maj and Tor Nessling foundation, Finnish Ministry of Agricultural and Forestry. We gratefully acknowledge technical support and help with the experiment given by Anthony Owusu-Sekyere, and also thank Dr Fred Stoddard for valuable comments on the manuscript.

\section{References}

Alfthan, G., Eurola, M., Ekholm, P., Venäläinen, E.R., Root, T., Korkalainen, K., Hartikainen, H., Salminen, P., Hietaniemi, V., Aspila, P. \& Aro, A. 2014. Effects of nationwide addition of selenium to fertilizers on foods, and animal and human health in Finland: From deficiency to optimal selenium status of the population. Journal of Trace Element in Medicine Biology http://dx.doi. org/10.1016/j.jtemb.2014.04.009.

Arnon, D. 1949. Copper enzymes in isolated chloroplasts: Polyphenoloxidase in Beta vulgaris. Plant Physiology 24: 1-15.

Bañuelos, G. \& Schrale, G. 1989. Plants that remove selenium from soils. California Agriculture 43: 19-20.

Baziramakenga, R. \& Simard, R.R. 1998. Low molecular weight aliphatic acid content of composted manures. Journal of Environmental Quality. 27: 557-561.

Chasteen, T.G. \& Bentley, R. 2003. Biomethylation of selenium and tellurium: microorganisms and plants. Chemical Reviewe 103: $1-25$.

Combs, G.F. 2004. Status of selenium in prostate cancer prevention. British Journal of Cancer 91: 195-199.

Combs, G.F. 2001. Selenium in global food systems. British Journal of Nutrition 85: 517-547.

De Souza, M.P., Chu, D., May, Z., Zayed, A.M., Ruzin, S.E., Schichnes, D. \& Terry, N. 1999. Rhizosphere bacteria enhance selenium accumulation and volatilization by Indian mustard. Plant Physiology 199: 565-573.

Djanaguiraman, M., Devi, D.D., Shanker, A.K., Sheeba, A. \& Bangarusamy, U. 2005. Selenium- an antioxidative protectant in soybean during senescence. Plant and Soil 272: 77-86.

Eich-Greatorex, S., Sogn, T.A., Falk Øgaard, A. \& Aasen, I. 2007. Plant availability of inorganic and organic selenium fertiliser as influenced by soil organic matter and pH. Nutrient Cycling in Agroecosystems 79: 221-231.

Eurola, M., Hietaniemi, V., Kontturi, M., Tuuri, H., Kangs, A., Niskanen, M. \& Saastamoinen, M. 2004. Selenium content of Finnish oats in 1997-1999: effect of cultivars and cultivation techniques. Agricultural and Food Science 13: 46-53.

Filek, M., Keskinen, R., Hartikainen, H., Szarejko, I., Janiak, A., Miszalski, Z. \& Golda, A. 2008. The protective role of selenium in rape seedlings subjected to cadmium stress. Journal of Plant Physiology 165: 833-844.

Freeman, J.L., Quinn, C.F., Lindblom, S.D., Klamper, E.M. \& Pilon-Smits, E.A.H. 2009. Selenium protects the hyperaccumulator Stanleya pinnata against black-tailed prairie dog herbivory in native seleniferous habitats. American Journal of Botany 96: 1075-1085.

Germ, M., Kreft, I. \& Osvald, J. 2005. Influence of UV-B exclusion and selenium treatment on photochemical efficiency of photosystem II, yield and respiratory potential in pumpkins (Cucurbita pepo L.). Plant Physiology and Biochemistry 43: 445-448.

Germ, M., Stibilj, V., Osvald, J. \& Kreft, I. 2007. Effect of selenium foliar application on chicory (Cichorium intybus L.). Journal of Agricultural and Food Chemistry 55: 795-798.

Grace, C., Hart, M. \& Brooker, P.C. 2006. Laboratory manual of the soil microbial biomass group. Rothamsted Research. p. 5-6.

Hanlon, E.A. 1993. Soil pH and electrical conductivity: A county extention soil laboratory manual. CIR1081. Soil and Water Department. Florida cooperative extension service. Institute of Food and Agricultural Sciences. University of Florida.

Hanson, B., Lindblom, S.D., Loeffler, M.L. \& Pilon-Smits, E.A.H. 2004. Selenium protects plants from phloem-feeding aphids due to both deterrence and toxicity. New Phytologist 162: 655-662.

Hartikainen, H., Ekholm, P., Piironen, V., Xue, T., Koivu, T. \& Yli-Halla, M. 1997. Quality of the ryegrass and lettuce yields as affected by selenium fertilization. Agricultural and Food Science 6: 381-387. 
Hartikainen, H. \& Xue, T. 1999. The promotive effect of selenium on plant growth as triggered by ultraviolet irradiation. Journal of Environmental Quality 28: 1272-1275.

Hassoun, B.S., Palmer, I.S. \& Dwivedi, C. 1995. Selenium detoxification by methylation. Research Communication in Molecular Pathology and Pharmacology 90: 133-142.

Hawrylak-Nowak, B. 2013. Comparative effects of selenite and selenate on growth and selenium accumulation in lettuce plants under hydroponic conditions. Plant Growth and Regulation 70: 149-157.

Hawrylak-Nowak, B. 2009. Beneficial effects of exogenous selenium in cucumber seedlings subjected to salt stress. Biology of Trace Element Research 132: 259-269.

Hawrylak-Nowak, B. 2008. Changes in anthocyanin content as indicator of maize sensitivity to selenium. Journal of Plant Nutrition 31: 1232-1242.

Jain, R., Verma, R., Singh, A., Chandra, A. \& Solomon, S. 2015. Influence of selenium on metallothionein gene expression and physiological characteristics of sugarcane plants. Plant Growth Regulation DOI 10.1007/s10725-015-0042-1.

Keskinen, R., Ekholm, P., Yli-Halla, M. \& Hartikainen, H. 2009. Efficiency of different methods in extracting selenium from agricultural soils of Finland. Geoderma 153: 87-93.

Kikkert, J. \& Berkelaar, E. 2013. Plant uptake and translocation of inorganic and organic forms of selenium. Archives of Environmental Contamination and Toxicology 65: 458-465.

Kong, L., Wang, M. \& Bi, D. 2005. Selenium modulates the activities of antioxidant enzymes, osmotic homeostasis and promotes the growth of sorrel seedlings under salt stress. Plant Growth Regulation 45: 155-163.

Lechenne, B., Reichard, U., Zaugg, C., Fratti, M., Kunert, J., Boulat, O. \& Monod, M. 2007. Sulphite efflux pumps in Aspergillus fumigatus and dermatophytes. Microbiology 153: 905-913.

Lindblom, S.D., Valdez-Barillas, J.R., Fakra, S.C., Marcus, M.A., Wangeline, A.L. \& Pilon-Smits, E.A.H. 2012. Influence of microbial associations on selenium localization and speciation in roots of Astragalus and Stanleya hyperaccumulators. Environmental and Experimental Botany 88: 33-42.

Lyons, G.H., Gene, Y., Soole, K., Stangoulis, J.C.R., Liu, F. \& Graham, R.D. 2009 Selenium increases seed production in Brassica. Plant and Soil 318: 73-80.

Meier, U. 2001. Growth stages of mono- and dicotyledonous plants, BBCH monograph. Oilseed rape section. 2Ed. German Federal Biological Research Center for Agriculture and Forestry.

Owusu-Sekyere, A., Kontturi, J., Hajiboland, R., Rahmat, S., Aliasgharzad, N., Hartikainen, H. \& Seppänen, M.M. 2013. Influence of selenium (Se) on carbohydrate metabolism, nodulation and growth in alfalfa (Medicago sativa L.). Plant and Soil 373: 541-552.

Padmaja, K., Prasad, D.D. \& Prasad, A.R. 1989. Effect of selenium on chlorophyll biosynthesis in mung bean seedlings. Phytochemistry 28: 3321-3324.

Pezzarossa, B., Remorini, D., Piccootino, D., Malagoli, M. \& Massasi, R. 2009. Effects of selenate addition on selenium accumulation and plant growth of two Prunus rootstock genotypes. Journal of Plant Nutrition and Soil Science 172: 261-269.

Pilon-Smits, E.A.H., Quinn, C.F., Tapken, W., Malagoli, M. \& Schiavon, M, 2009. Physiological functions of beneficial elements. Current Opinion in Plant Biology 12: 267-274.

Prasad, D.P.H. \& Prasad, A.R.K. 1987. Effects of lead and mercury on chlorophyll synthesis in mung bean seedlings. Phytochemistry 26: 881-884.

Rayman, M.P. 2002. The argument for increasing selenium intake. Proceeding in the Nutrition Society 61: 203-215.

Seppänen, M.M., Kontturi, J., Heras, I.L., Madrid, Y., Cámara, C. \& Hartikainen, H. 2010. Agronomic biofortification of Brassica with selenium- enrichment of SeMet and its identification in Brassica seeds and meal. Plant and Soil 337: 273-283.

Seppänen, M.M., Turakainen, M. \& Hartikainen, H. 2003. Selenium effects on oxidative stress in potato. Plant Science 165: 311-319.

Sharma, V., Nehru, B., Munshi, A. \& Jyothy, A. 2010. Antioxidant potential of curcumin against oxidative insult induced by pentylenetetrazol in epileptic rats. Methods and Findings in Experimental and Clinical Pharmacology 32: 227-32.

Singh, M., Singh, H. \& Bhandari, D.K. 1980. Interaction of selenium and sulphur on the growth and chemical composition of raya. Soil Science 129: 238-244.

Srikanth-Lavu, R.V., Schepper, V.D., Steppe, K., Majeti, P.N.V., Tack, F. \& Laing, G.D. 2013. Use of selenium fertilization for production of Se- enriched Kenaf (Hibiscus cannabinus): Effect on Se concentration and plant productivity. Journal of Plant Nutrition and Soil Science 176: 634-639.

Stavridou, E., Young, S.D. \& Thorup-Kristensen, K. 2012. The effect of catch crop species on selenium availability for succeeding crops. Plant and Soil 351: 149-160.

Stolz, J.F., Basu, P., Santini, J.M. \& Oremland, R.S. 2006. Arsenic and selenium in microbial metabolism. Annual Review in Microbiology 60: 107-130.

Terry, N., Zayed, A.M., de Souza, M.P. \& Tarun, A.S. 2000 Selenium in higher plants. Annual Review of Plant Physiology and Plant Molecular Biology 51: 401-32.

Trinsourtrot, I., Recous, S., Mary, B. \& Nicolardot, B. 2000. C and N fluxes of decomposing ${ }^{13} \mathrm{C}$ and ${ }^{15} \mathrm{~N}$ Brassica napus L. effects of residue composition and $\mathrm{N}$ content. Soil Biology and Biochemistry 32: 1717-1730.

Turakainen, M., Hartikainen, H. \& Seppänen, M.M. 2004. Effects of selenium treatments on potato (Solanum tuberosum L.) growth and concentrations of soluble sugars and starch. Journal of Agricultural and Food Chemistry 52: 5378-5382.

Vallini, G., Di Gregorio, S. \& Lampis, S. 2005. Rhizosphere-induced selenium precipitation for possible applications in phytoremediation of Se polluted effluents. Zeitschrift für Naturforschung C 60: 349-356. 
Whanger, P.D. 2004. Selenium and its relationship to cancer: an update. British Journal of Nutrition 91: 11-28.

White, P.J., Bowen, H.C., Parmaguru, P., Fritz, M., Spracken, W.P., Spiby, R.E., Meacham, M.C., Mead, A., Harriman, M., Trueman, L.J., Smith, B.M., Thomas, B. \& Broadley, M.R. 2004. Interactions between selenium and sulphur nutrition in Arabidopsis thaliana. Journal of Experimental Botany 55: 1927-1937.

Xue, T. \& Hartikainen, H. 2000. Association of antioxidative enzymes with the synergistic effect of selenium and UV irradiation in enhancing plant growth. Agricultural and Food Science 9: 177-186.

Xue, T., Hartikainen, H. \& Piironen, V. 2001 Antioxidative and growth- promoting effect of selenium on senescing lettuce. Plant and Soil 237: 55- 61.

Zayed, A., Lytle, C.M. \& Terry, N. 1998. Accumulation and volatilization of different chemical species of selenium by plants. Planta 206: 284-292.

Zhang, M., Tang, S., Huang, X., Zhang, F., Pang, Y., Huang, Q. \& Yi, Q. 2014. Selenium uptake, dynamic changes in selenium content and its influence on photosynthesis and chlorophyll fluorescence in rice (Oryza sativa L.). Environmental and Experimental Botany 107: 39- 45. 